\title{
The General Trend of Temperatures in the Central and Southern Regions of Iraq and to Predict It's in the Future
}

\author{
Jawad Kadhim Obaid al Hesnawy, Nadia Rhman Mohammed Al-Khaqani \\ Department of Geography, College of Education for Girls, University of Kufa, Najaf, Iraq \\ Email address: \\ bmwaa19912015@yahoo.com(N. R. M. Al-Khaqani)

\section{To cite this article:} \\ Jawad Kadhim Obaid al Hesnawy, Nadia Rhman Mohammed Al-Khaqani. The General Trend of Temperatures in the Central and Southern \\ Regions of Iraq and to Predict It's in the Future. International Journal of Environmental Monitoring and Analysis. \\ Vol. 6, No. 1, 2018, pp. 13-17. doi: 10.11648/j.ijema.20180601.12
}

Received: July 6, 2017; Accepted: February 11, 2018; Published: March 14, 2018

\begin{abstract}
The study aims to detect the change in the temperature Central and Southern Regions of Iraq, it has been shown that the temperature of the study area climate for the period (1981- 2014) has increased by (1.41 m), also revealed climate prediction of the future for the time period of the stations the study area than a year $(2015-2065)$, that there is a gradual rise in temperatures is thermally of the study area, the temperature recorded in 2015 , the rate of temperature $(25.61 \mathrm{~m})$ while the rate in $2065(28.93 \mathrm{~m})$ and that the increase in the degree of rate heat during the fifty years to come will be $(3.32 \mathrm{~m})$.
\end{abstract}

Keywords: Degree Temperature, Predict Future Temperature, Climate Changes

\section{Introduction}

The contemporary climate of the land of great importance, because most of the liturgical changes associated with the origins and evolution of the climate elements, and that Iraq contemporary climate does not belong to one type of climate types (continental or orbital), given the disparity and differences between its divisions in terms of temperature, rainfall and other climatic conditions, So-called continental climate and semi-tropical, but this label is not sufficient to describe Iraq contemporary climate, it might be tropical in terms of heat, but not be the case in terms of the amount of rainfall and the off-season, so the study area is characterized by extremism in the climatic elements, and that those changes are in response to heat depends on each element of the climate elements or the sum of these combined elements with each other but they are at variable rates, and the availability of developments in climate significant changes related to climate elements of science, especially the heat element of them, which is directly responsible for all the daily events of the climate, so the Earth's climate responsible for it temperatures has seen great changes over the ancient times until it reached what it now, and put a lot of studies additional possibilities such as the likelihood of future changes in temperature, such as heat waves, Mertzon in saying that the changes may have occurred since centuries as well as the emission of greenhouse gases since the twentieth century and which has expanded in the current century and will result in the future.

\section{The Limits of the Study Area}

Divided border which are studied searched on the basis of two sections, namely the limits of spatial represented the study area, the central and southern region of Iraq, located between latitudes $\left(35^{\circ} 13^{-} 01 \_28^{\circ} 56^{-} 16\right)$ to the north, and longitudes $\left(38^{\circ} 40^{-} 10^{-} 48^{\circ} 50^{-} 44\right)$ to the east, and bounded on the north undulating region and the north-west Syria, and from the south and south-east Arabian Gulf, Kuwait and Saudi Arabia to the east by Iran on the west by Jordan, and the area was (307.099) $\mathrm{km}^{2}$, which make up about $71 \%$ of the area of Iraq, it has been studying the region within (11) weather station

Major illustrated (Table 1 and Map 1).

The most temporal boundaries, study and analyze the temperature and predicting the future in the central and southern regions of

Iraq during the period (2014_1981), and divided on the basis of climatic periods, which are represented as follows:.

$\checkmark$ the general trend (1981_2014) $>$ the first-term climatic (1981 1991)

$\checkmark$ second term climatic (1992_ 2002) $>$ third term climatic (2003_2014) 
Table 1. The stations included in the study.

\begin{tabular}{llllll}
\hline No. & Station name & The latitude (degrees) East & Longitude (degrees) north & Altitude above sea level (meters) & Station number Alania \\
\hline 1 & Baghdad & $33^{\circ} 18$ & $44^{\circ} 24$ & 31.7 & 650 \\
2 & Rutba & $33^{\circ} 02$ & $40^{\circ} 17$ & 630.8 & 642 \\
3 & Karbala & $32^{\circ} 34$ & $44^{\circ} 03$ & 29 & 656 \\
4 & Hilla & $32^{\circ} 27$ & $44^{\circ} 27$ & 27 & 657 \\
5 & Hai & $32^{\circ} 08$ & $46^{\circ} 02$ & 17 & 665 \\
6 & Najaf & $31^{\circ} 57$ & $44^{\circ} 19$ & 53 & 670 \\
7 & Diwaniya & $31^{\circ} 57$ & $47^{\circ} 10$ & 20 & 672 \\
8 & Amara & $31^{\circ} 50$ & $45^{\circ} 16$ & 9.5 & 680 \\
9 & Samawa & $31^{\circ} 16$ & $46^{\circ} 14$ & 11.4 & 674 \\
10 & Nasiriyah & $31^{\circ} 01$ & $47^{\circ} 47$ & 2.6 & 676 \\
11 & Basra & $30^{\circ} 31$ & 590 & \\
\hline
\end{tabular}

Source: Ministry of Transport, Public Meteorological Organization and Seismology, climate department (unpublished data), Baghdad, 2014.

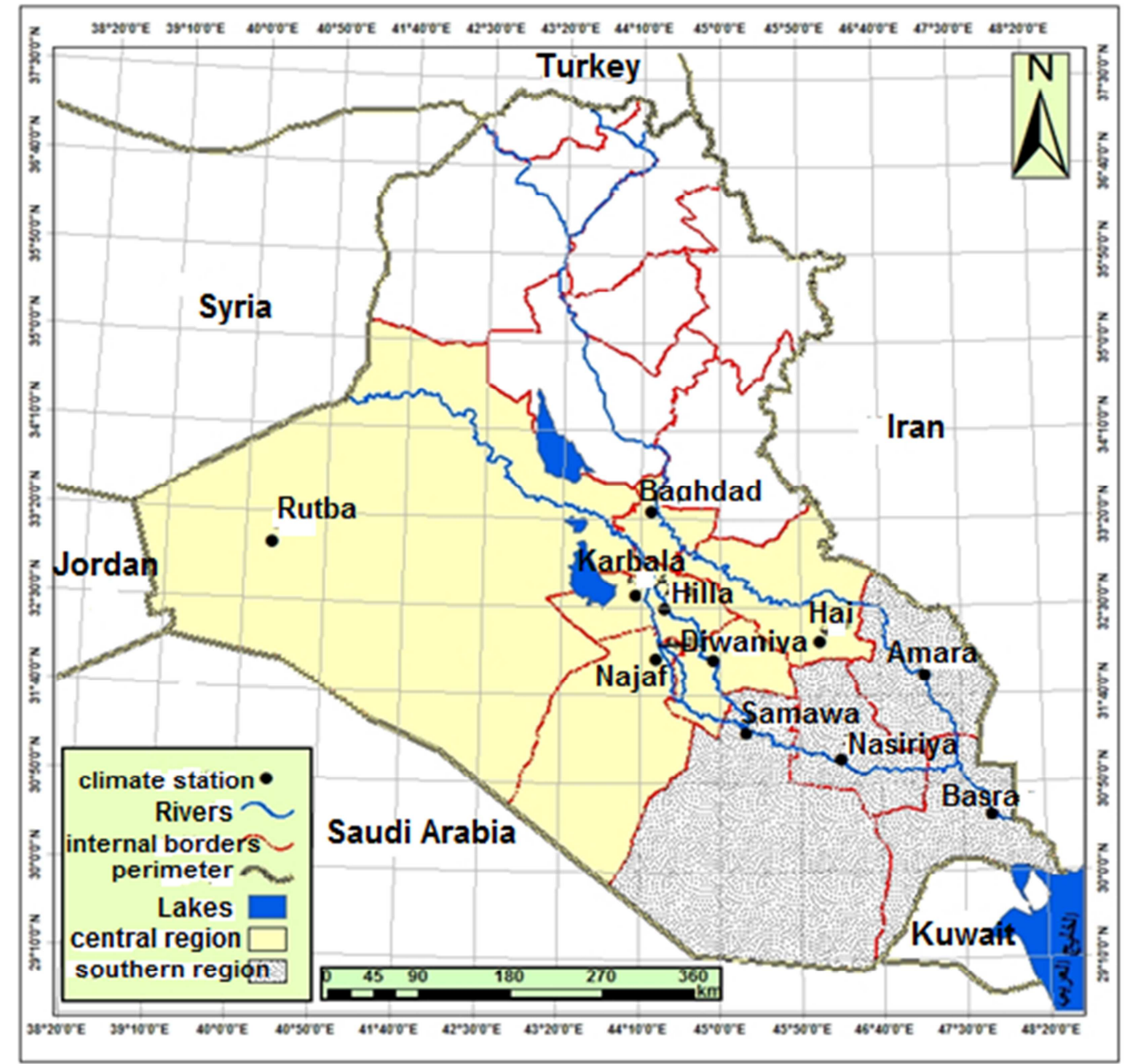

Source: General Survey Authority, the administrative map of Iraq, 2010, depending on the visual space, satellite Landsat.7, $2006 \mathrm{~m}$.

Figure 1. The geographic distribution of climate stations in the study approved.

First: The direction of rates of temperatures in the study area over a period of general direction and climatic periods.

A - the direction of temperatures over a period of general direction:

The temperatures of the important climatic elements and fundamental influence on the climate of the region, directly or indirectly, and is a direct impact in terms of processes of evaporation caused by the Earth's surface that by increasing the evaporation of wetlands and aquatic surfaces rates, while the indirect influence shows through its impact in and other climatic elements of air and moisture and wind and rain and other pressure, as it is any change in temperature no matter how big or small in accordance influential in various liturgical phenomena in the study area, and Iraq from 
countries with high temperatures reflected its impact on the natural and human phenomena such as drought (4), and given the importance of this element must follow up the general rates of temperature during the period of the general trend (1981-2014) and during the three climatic periods, it is through (Table 2), which shows the general trend of temperatures and climatic periods, we find that the Basra terminal topped the rest of the area stations study in recording the highest rate of temperature within a period of general direction as well as climatic periods, as was (26.20, $25.28,26.44,26.28 \mathrm{~m}$ ) respectively, while the lowest rate was Rutba station recorded temperature was $(20.88,19.52$, $20.16,22.78 \mathrm{~m})$ respectively The remaining provinces ranged general trend of temperature is between $(23,78$ -
$25,78 \mathrm{~m}$ ), either climatic periods also there is variation in their degrees, ranging in length between the first (22.56 to $24.92 \mathrm{~m}$ ) in the provinces of Baghdad and the al-hai station, either the second period ranged temperatures (22.99 - 25.65 $\mathrm{m})$ in the provinces of Baghdad and Nasiriyah, while the third period recorded temperatures ranged from (23.77 $26,77 \mathrm{~m}$ ) in the provinces of Baghdad, Nasiriyah, When you follow the general trend of the temperature of the three time-periods, we find there is a discrepancy, but not a big contrast in temperature, due to the proximity of those provinces and regions from each other, and the lack of barriers or natural barriers in the study area lead to high or low temperatures.

Table 2. The general trend and periods of climatic temperatures stations study area (1981-2014).

\begin{tabular}{lllll}
\hline Station & General trend (1981-2014) & For the first time (1981-1991) & Second term (1992-2002) & Third term (2003-2014) \\
\hline Baghdad & 22.56 & 22.99 & 23.77 & 22.78 \\
Rutba & 19.52 & 20.16 & 24.50 & 20.88 \\
Karbala & 24.43 & 23.75 & 23.86 & 24.98 \\
Hilla & 23.78 & 23.24 & 25.41 & 24.19 \\
Hai & 25.36 & 24.92 & 24.50 & 25.71 \\
Najaf & 24.61 & 23.92 & 24.66 & 25.35 \\
Diwaniya & 24.64 & 24.22 & 25.18 & 25.02 \\
Amara & 25.14 & 24.49 & 24.60 & 25.70 \\
Samawa & 24.98 & 24.64 & 25.65 & 25.63 \\
Nasiriyah & 25.76 & 24.77 & 26.44 \\
Basra & 26.20 & 25.28 & & 26.77 \\
\hline
\end{tabular}

Source: Ministry of Transport, Public Authority for meteorological and seismic monitoring, climate department, unpublished data, Baghdad, 2014.

B - the direction of temperatures across climatic periods

Through what is referred to for the general trend of rising temperatures for the period (1981-2014) within the study area plants in general, it shall divide the duration of the study to the extended climatic order to find out their rates in time and space, it is through (Table 3), which shows the temperature distribution by periods three climate we find that the third climatic period (2003-2014) recorded the highest temperature reached $(25.16 \mathrm{~m})$ while the first recorded climatic period (1981-1991) the lowest rate of temperatures reached $(23.75$ $\mathrm{m})$ and recorded the second climatic period (1992-2002 ) rate of temperature reached $(24.36 \mathrm{~m})$, and that the overall rate of degrees temporal temperature in the study area has reached $(24.42 \mathrm{~m})$, and by tracking the first second and third temporally periods of time, we find that the temperature in the study area has increased by $(0.61 \mathrm{~m})$ in the second period for the first, and the third time duration rose for a second term by reaching $(0.80 \mathrm{~m})$, and this means that the temperature has risen temporally in the study area from the year (1981-2014), this amounted to rise in temperature (1.41 $\mathrm{m})$, and this is what confirms the global studies confirmed that the temperature of the earth has risen by two degrees Celsius during the twentieth century.

Table 3. The annual rate of temporal temperature within three climatic periods in the study area.

\begin{tabular}{|c|c|c|c|c|c|}
\hline \multicolumn{2}{|c|}{ The first period (1981-1991) } & \multicolumn{2}{|c|}{ Second term (1992-2002) } & \multicolumn{2}{|c|}{ Third term (2003-2014) } \\
\hline Year & The annual rate of the year & Year & The annual rate of the year & Year & The annual rate of the year \\
\hline 1981 & 23.93 & 1992 & 22.59 & 2003 & 24.88 \\
\hline 1982 & 22.77 & 1993 & 23.72 & 2004 & 24.42 \\
\hline 1983 & 23.14 & 1994 & 24.44 & 2005 & 24.62 \\
\hline 1984 & 23.55 & 1995 & 24.12 & 2006 & 24.72 \\
\hline 1985 & 23.82 & 1996 & 24.74 & 2007 & 24.85 \\
\hline 1986 & 24.22 & 1997 & 23.73 & 2008 & 24.99 \\
\hline 1988 & 23.75 & 1999 & 25.14 & 2010 & 26.19 \\
\hline 1989 & 23.93 & 2000 & 24.67 & 2011 & 24.64 \\
\hline 1990 & 24.05 & 2001 & 25.12 & 2012 & 25.43 \\
\hline 1991 & 23.88 & 2002 & 24.70 & 2013 & 24.80 \\
\hline Average & 23.75 & Average & 25.22 & 2014 & 25.22 \\
\hline ----------. & ------------ & ------------ & ------------ & Average & 25.16 \\
\hline
\end{tabular}

Source: Ministry of Transport, Public Authority for meteorological and seismic monitoring, climate department, unpublished data, Baghdad, 2014. 
And (Table 4) shows that the annual rate shows the temperature spatially within Central and South Stations Region of Iraq, where the Basra Governorate recorded the highest thermal spatial rate, reaching an average of the three periods $(26.18 \mathrm{~m})$, while the Rutba area recorded the lowest thermal rate where I am, where the temperature reached spatially during the three periods of time $(20.82 \mathrm{~m})$, and the spatial average temperatures for the year reached in the study area first, second and third periods of time $(12.69,24.35$, $25.15 \mathrm{~m})$ respectively, while spatial average rate for temperatures to the provinces was $(24.44 \mathrm{~m})$.

Table 4. Annual rate spatial temperature within three climatic periods in the study area.

\begin{tabular}{lllll}
\hline Station & $\begin{array}{l}\text { The first time } \\
(\mathbf{1 9 8 1 - 1 9 9 1 )}\end{array}$ & $\begin{array}{l}\text { Second term } \\
(\mathbf{1 9 9 2 - 2 0 0 2 )}\end{array}$ & $\begin{array}{l}\text { Third term } \\
\mathbf{( 2 0 0 3 - 2 0 1 4 )}\end{array}$ & $\begin{array}{l}\text { Spatial } \\
\text { average }\end{array}$ \\
\hline Baghdad & 22.99 & 23.77 & 23.10 & 22.56 \\
Rutba & 20.16 & 22.78 & 20.82 & 19.52 \\
Karbala & 23.75 & 24.50 & 24.98 & 24.41 \\
Hilla & 23.24 & 23.86 & 24.19 & 24.02 \\
Hai & 25.41 & 25.71 & 24.92 & 25.34 \\
Najaf & 23.92 & 24.50 & 25.35 & 24.59 \\
Diwaniya & 24.22 & 24.66 & 25.02 & 24.63 \\
Amara & 24.49 & 25.18 & 25.70 & 25.12 \\
Samawa & 24.64 & 24.60 & 25.63 & 24.95 \\
Nasiriyah & 24.77 & 25.65 & 26.77 & 25.73 \\
Basra & 25.28 & 26.44 & 26.82 & 26.18 \\
Average & 23.69 & 24.35 & 25.15 & 24.44 \\
\hline
\end{tabular}

Source: Ministry of Transport, Public Authority for meteorological and seismic monitoring, climate department, unpublished data, Baghdad, 2014

Second: to predict future temperatures, Central and South of the region for the period (2015-2065).

In the past five decades all continents experienced a major climatic fluctuations, was and still is the subject of several studies on the occurrence and cause of continuity, too, has this climatic disturbances caused several devastating natural disasters, such as hurricanes and melting ice and rain, floods, droughts, etc., and these climatic changes have destabilized Systems the environment, and are estimated exposure and sensitivity to these future climate change, according to mathematical models under different studies, and suffering Iraq, like all countries of the world from the effects that climate change including imposed by its geographical location and characteristics of ecological regulations as Iraq is located in the west of the continent of Asia between two contrasting making it under the influence of climate Mediterranean medley, cool rainy winters and dry and hot summers, has Meteorological confirmed in recent decades that the desert climate and semi-desert crawling in the direction of Iraq from north to south and from weird to choke, and warn of climate predictions and expectations of future worsen the desert climate creep during the second half of the atheist century twenty, and those required in the climate forecasts for the coming decades to be at the local level, depending on climatic geographical scales accurate and appropriate and sensitive to all climatic changes that occur at all levels.
Whatever reached the human ability to know the natural phenomena, follow up and try to predict, it remains powerless, especially in the climate science, which is a dynamic science characterized by change and development, but this does not preclude follow its changes and monitoring, especially with the technical development and modern development of statistical methods, mathematical methods that It allows building climate model to see the changes that will occur in the temperatures of the study area in the coming decades.

The results showed predictable for a period (2065-2015) any term (50 years) and as shown in (Table 5) that temperatures recorded the lowest rate in the year (2015) as the percentage $(25.61 \mathrm{~m})$, while the year (2065) temperatures and high-reaching that heat $(28.93 \mathrm{~m})$, and that this change in temperature and rainfall reflections unexpected to all fields, notably the transformation of land to the decertified areas, Temperatures worsening rise could have caused the change in weather conditions from the air and the winds and the moisture and increase the pressure dust storms, and that this change consequences at different levels, including social, economic, political, and it can be said that this in future climate is expected will cause the creation of a lot of issues that are today the world is unaware of them, no matter how accurate these predictions, they help in the development of plans for various sectors, and thus contribute to open new horizons for future adaptation.

Table 5. To predict the future direction of the temperature according to standard rain benchmark SPI stations study area.

\begin{tabular}{llllllll}
\hline Year & Temp & Year & temp & Year & temp & Year & temp \\
\hline 2015 & 25.61 & 2028 & 26.47 & 2041 & 27.30 & 2054 & 28.19 \\
2016 & 25.71 & 2029 & 26.54 & 2042 & 27.34 & 2055 & 28.25 \\
2017 & 25.75 & 2030 & 26.59 & 2043 & 27.38 & 2056 & 28.32 \\
2018 & 25.79 & 2031 & 26.68 & 2044 & 27.55 & 2057 & 28.38 \\
2019 & 25.85 & 2032 & 26.69 & 2045 & 27.68 & 2058 & 28.45 \\
2020 & 25.93 & 2033 & 26.78 & 2046 & 27.71 & 2059 & 28.52 \\
2021 & 26.03 & 2034 & 26.87 & 2047 & 27.79 & 2060 & 28.59 \\
2022 & 26.13 & 2035 & 26.94 & 2048 & 27.82 & 2061 & 28.66 \\
2023 & 26.21 & 2036 & 27.03 & 2049 & 27.87 & 2062 & 28.73 \\
2024 & 26.29 & 2037 & 27.10 & 2050 & 27.94 & 2063 & 28.79 \\
2025 & 26.37 & 2038 & 27.17 & 2051 & 28.00 & 2064 & 28.86 \\
2026 & 26.45 & 2039 & 27.21 & 2052 & 28.07 & 2065 & 28.93 \\
2027 & 26.43 & 2040 & 27.26 & 2053 & 28.13 & ------ & ------- \\
\hline
\end{tabular}

Source: researcher works depending on the EXCEL program.

\section{Conclusions}

1. It is clear from the study by comparing the three periods of time with each other, that there is variation in temperature across the three-term climate, as the temperature rose in the first term climatic limits $(0.61 \mathrm{~m})$, while the rose in the third climate-term by the second $(0.80 \mathrm{~m})$.

2. recorded climatic period (1981-2014) rates of temperature spatially varied between the provinces of the study area, where Basra station recorded the highest rate where temperature reached $(26.18 \mathrm{~m})$ while the lowest rate of temperature where Rutba station recorded reaching that rate 
in the heat $(20.82 \mathrm{~m})$.

3. showed record rainfall index future to predict that the study area will see a marked increase in temperatures in the coming decades.

\section{References}

[1] Ali Sahib Talibal-Moussawi, Abdul Hassan Madfon, Iraqclimate, Girls College of Education,, University of Kufa, Libra Press, 2013, p. 321.

[2] Al-Humairi, Abdul Redha Abdullah Aboud, bitter thirst in Mesopotamia, General of Cultural Affairs, Baghdad, 2013.
[3] Al-dsaa, Salar Ali, Iraq's ancient climate and contemporary, General of Cultural Affairs, Baghdad, 2013.

[4] Al-Samarrai, Qusay Abdul Majid, the principles of weather and climate, Dar Yazouri, Amman, Jordan, 2008.

[5] General Survey Authority, the administrative map of Iraq, 2010, depending on the visual space, satellite Landsat.7, 2006.

[6] The Ministry of Transport, Public Authority for meteorological and seismic monitoring, climate department, unpublished data, Baghdad, 2014. 